\section{Environmental stewardship contributes more to the Massachusetts economy than whale watching, fin- fish fisheries}

Commercial fishery interests and other extractive industries typically dominate discussions for environmental decision-making for the oceans and coasts. These industries can claim millions of dollars in benefits to local communities by simply adding up their sales. But there are lots of other coastal activities with less visible economic impacts. How can the economic benefits of marine stewardship and conservation activities be estimated? The authors used donations to coastal and marine civil society organizations, and volunteer efforts, to provide a conservative estimate of the economic benefits provided to the state.

Publicly-available budget data for environmental organizations known to be involved in marine conservation activities provided part of the solution, thanks to including the amount of donations these groups received. The other part came from human effort spent volunteering to coastal environment causes. Combined, these activities came to $\$ 178.9$ million in just 2014. The figure raises to $\$ 281.9$ million if environmental organizations that also focus on non-marine issues are included. Importantly, this "study does not explicitly include two essential forms of stewardship: direct private-sector efforts, such as donations by companies in Massachusetts, and direct government expenditures on marine stewardship, such as government salaries and policy-induced measures" which could substantially increase economic impacts.

By comparison, the commercial fin-fish industry in Massachusetts accounts for $\$ 105.4$ million; whale watching comes to $\$ 110.8$ million. The authors note: "Although donations to marine environmental stewardship and the accompanying value of volunteer hours were larger than revenues generated by whale watching and extractive fishing industries, these activities are almost always overlooked in traditional decision making, a pattern that is repeated at the national level." The authors refer to this effect as "stranded capital" or "or the flow of stewardship action and revenue that is often ignored - 'stranded' - during economic decision making."

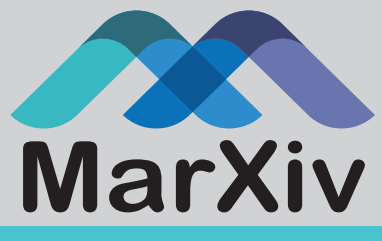

This is a summary of: Stranded capital: environmental stewardship is part of the economy, too

Accessible at: https://marxiv.org/jyvge

Authors: Joe Roman, Verna DeLauer, Irit Altman, Brendan Fisher, Roelof Boumans, Les Kaufman

Added to MarXiv: May 2018

Published: Frontiers in Ecology and the Environment, 2018

Suggested Citation: Environmental stewardship contributes more to the Massachusetts economy than whale watching, fin-fish fisheries. OCTO (2018). DOI: 10.31230/osf.io/h43af

See more MarXiv summaries at https://www.marxivinfo.org/ summaries

Join the MarXiv Summaries monthly newsletter at https:// oct.to/marxivsum

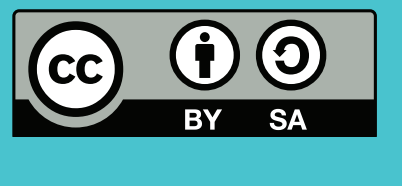

MarXiv is an ОСТO Initiative
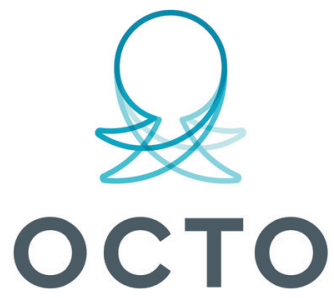

OPEN COMMUNICATIONS FOR THE OCEAN 